\title{
AN UNUSUAL SAR ARC OBSERVED DURING RING CURRENT DEVELOPMENT, 4 AUGUST 1972
}

\author{
G. G. SHEPHERD, ${ }^{*}$ L. H. BRACE, $\dagger$ J. R. BURROWS, $\neq$ J. H. HOFFMAN, 8 H. G. JAMES, $\|$ \\ D. M. KLUMPAR, $\S$ A. F. NAGY, $\uparrow$ E. STATHOPOULOS** and J. H. WHTTTEKER\|
}

(Received 16 July 1979)

\begin{abstract}
Measurements made from the ISIS-II spacecraft at $1400 \mathrm{~km}$ and ground-based measurements from New Zealand provide a detailed description of an unusual SAR arc observed at dusk on 4 August 1972, during the growth phase of the ring current. Proton precipitation was observed over a latitude range of a few degrees, with electron temperature enhancements throughout the region but espeically at its boundaries, and an $F$-region trough was present at the equatorward boundary. SAR arcs usually occur at equatorward proton boundaries but this one appeared at the poleward boundary, which seems to have given rise to a number of unusual features. Characteristics unique to this event are a high flux of low energy electrons at the SAR arc location, associated with an upward field-aligned current there, and a "slot" in the ambient electron density, which falls to $5 \%$ of the background density over a region of $1.5 \mathrm{~km}$ half-width. Immediately poleward of the low energy electron flux, intense whistler mode noise $(0.1-0.4 \mathrm{MHz})$ is evident. The $6300 \AA$ emission, which has a total intensity of $10.6 \mathrm{kR}$, appears divided into two components, one at $285 \mathrm{~km}$ excited by the low energy electrons, and the other at $400 \mathrm{~km}$, excited thermally by the electron gas. Comparisons are made with $S^{3}-A$ spacecraft observations made in the equatorial region at the same time, with ISIS-II observations of a more normal SAR arc, and with other observations reported in the literature. The kinetic Alfvén wave process described by Hasegawa and Mima (1978) seems a candidate for the acceleration of these low energy electrons, but it is not possible to entirely exclude the alternative of an auroral-type acceleration process.
\end{abstract}

\section{INTRODUCTION}

A spectacular $6300 \AA$ feature was described by Shepherd et al. (1976), in a report on the optical emissions and related particle characteristics observed at mid-latitudes during the August 1972, geomagnetic storm. It was observed in a single ISIS-II pass, at dusk, located at the poleward boundary of a broader region of isotropic precipitating protons, and its occurrence there was ascribed to the encounter of inwardly diffusing ring current protons with the plasmapause. A detailed

\footnotetext{
* Department of Plasma Physics, Royal Institute of Technology, S100-44, Stockholm, and Uppsala Ionospheric Observatory, Uppsala, Sweden.

† Goddard Space Flight Center, Greenbelt, MA 20771, U.S.A.

¥ Herzberg Astrophysical Institute, National Research Council, Ottawa, Canada K1A 0R6.

$\S$ Center for Space Sciences, University of Texas at Dallas, Richardson, TX 75082, U.S.A.

|| Department of Communications, Communications Research Center, Ottawa, Canada, K2H 8S2.

T Department of Atmospheric and Oceanic Science, University of Michigan, Ann Arbor, MI 48109, U.S.A.

** Center for Research in Experimental Space Science, York University, Toronto, Canada, M3J 1 P3.
}

examination of all available ISIS-II instrument responses was subsequently undertaken, along with the groundbased observations made simultaneously from New Zealand, where the telemetry was acquired, and the results of that examination are described here. Brace et al. (1974) reported on ISIS-II observations during this storm on the dawn side of the orbit, which also included a possible SAR arc occurrence.

Since Cole's (1965) original proposal that the storm-time ring current provides the energy source for SAR arcs, this idea has been explored by a number of workers. Since SAR arcs are stable over intervals of hours they are amenable to multidimensional quantitative observations, and a careful comparison with theory should be possible. The progress up until 1974 has been reviewed by Rees and Roble (1975). It turns out that only a few SAR arcs have been studied in detail so that much of our current knowledge about SAR arcs stems from only a few occurrences. While a number of basic characteristics have been established, a number of important points remain to be resolved. The specific energy transfer mechanism from the protons to the excited $O\left({ }^{1} D\right)$ atoms has not been definitely established, though it seems almost certain that heating 
of the ionospheric electron gas is an intermediate step through thermal excitation of the atomic oxygen. In the last few years, even the composition of the ring current ions has been questioned, and both $\mathrm{O}^{+}$and $\mathrm{H}^{+}$have been observed precipitating during major storms. The relative importance of charge exchange, ion-electron Coulomb collisions, and ion cyclotron resonance in ring current energy loss remains to be established. At the present time one can only be sure that the real situation is more complex than the model outlined by Cole (1965).

In this report, detailed observations of a monochromatic $10.6 \mathrm{kR}, 6300 \AA$ feature are described, probably more detailed than for any previous SAR arc. A number of unusual features, including soft electron precipitation and a fieldaligned current were observed, and initially it was not clear whether this was simply because the arc was unusual, or whether it was because the measurements were more detailed than those made before. During the study it was established that these unusual features were not evident in "normal" SAR arcs, and so while the study of this 4 August SAR arc is interesting in its own right, it is not clear to what extent an understanding of the mechanisms involved in it contribute to the understanding of SAR arcs in general. We must leave unresolved at this time whether the unusual characteristics were simply related to an order of magnitude greater $6300 \AA$ emission intensity, or whether the excitation processes involved here were entirely different.

\section{OVERALL DESCRIPTION OF RESULTS}

The spacecraft observations were all made from ISIS-II, whose instruments have been described briefly by Shepherd et al. (1973), and in more detail in references cited therein. At the time of the observations the spacecraft was in a nearly dawndusk orbit, that was near-circular at $1400 \mathrm{~km}$. The spacecraft spin axis was aligned perpendicular to the orbit plane, permitting measurements of the East-West (E-W) magnetic field component, and of ion densities.

A composite display of most of the results, shown at low resolution through the entire region of interest is shown in Fig. 1, and is described beginning with the bottom frame and moving upward. The bottom frame shows the spectral noise power density delivered by the antennas to the sounder receiver, plotted as a function of time for two representative frequencies, 0.2 and $0.4 \mathrm{MHz}$. These data are discussed at the end of Section 3.

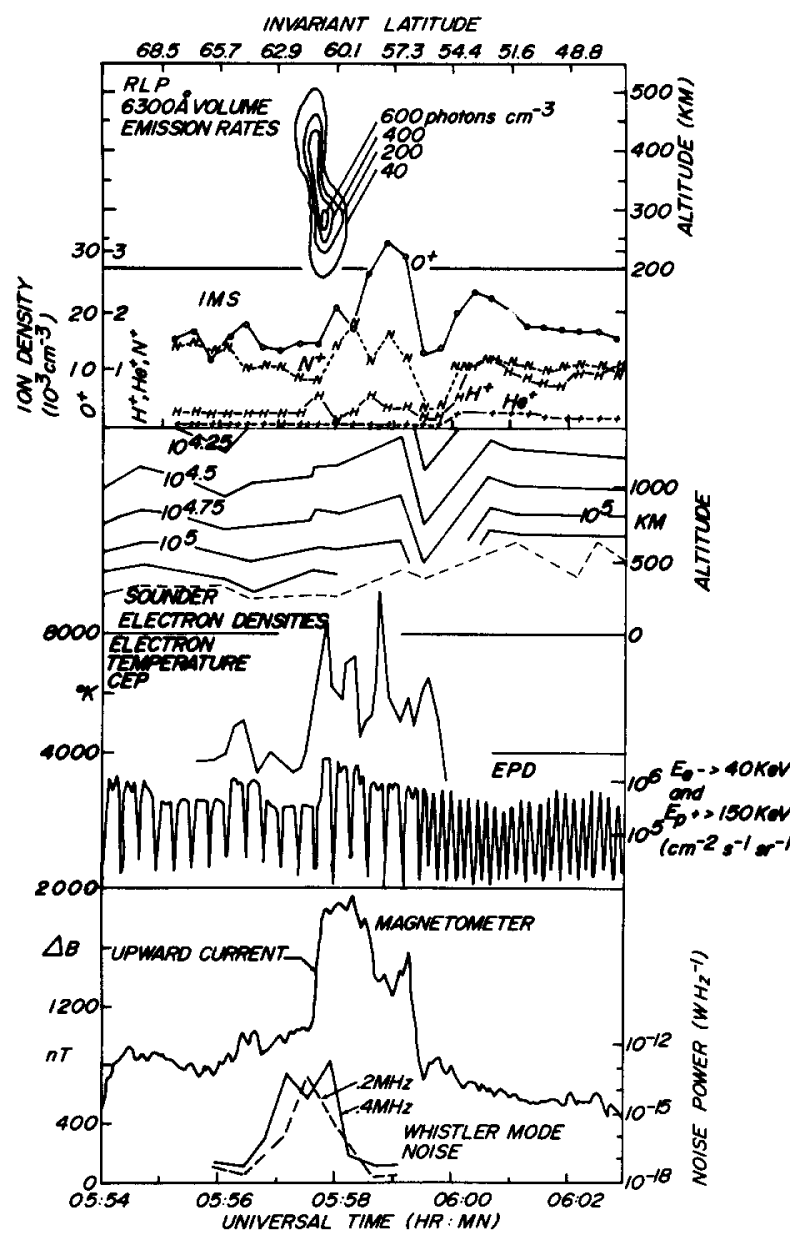

Fig. 1. COMPOSITE PRESENTATION OF ISIS-II DATA FOR 4 AUGUST 1972 FROM 05:54 TO 06:03 U.T. CORRESPONDING TO $48.2-69.3^{\circ}$ INVARIANT LATITUDE.

The frames from top to bottom are: red line photometer (RLP) vertical profiles of $6300 \AA$ volume emission rate, ion mass spectrometer (IMS) ion densities measured at the spacecraft, vertical profiles of electron density measured with the topside sounder; the following are all measured at the spacecraft, electron temperature with the cylindrical electrostatic probe (CEP), proton flux of $E>$ $150 \mathrm{keV}$ measured with the energetic particle detector (EPD), E-W component of magnetic perturbation measured with the magnetometer, and noise power at 0.2 and $0.4 \mathrm{MHz}$

The bottom frame also shows the $\mathrm{E}-\mathrm{W}$ magnetic perturbation, $\Delta B$, obtained from the axial magnetometer as described by Burrows et al. (1976). The slope of the positive (westward) perturbation at $60.8^{\circ}$ invariant (at $05: 57 / 45$ U.T., this notation is used to indicate $\mathrm{h}: \mathrm{min} / \mathrm{s}$ throughout the paper) corresponds to an upward field-aligned current of $14.5 \mu \mathrm{amp} \mathrm{m}^{-2}$ extending from $57 / 42$ to $57 / 48$. It 
occurs just at the onset of a region of isotropic protons $(E<150 \mathrm{keV})$ measured by the EPD (energetic particle detector) and shown in the frame above. The modulation in the detected flux results from the spacecraft rotation since the detector is mounted perpendicular to the spin axis. The sharp deep minima correspond to viewing down the field line, and the flat topped maxima indicate an isotropic distribution, although the shallow minima in the centre do show a loss cone associated with the opposite hemisphere. The detector responds to electrons with $E>40 \mathrm{keV}$ as well as to protons with $E>150 \mathrm{keV}$. By comparing the response of this detector with that of other purely electron detectors it is found (Shepherd et al., 1976) that the flux enhancements at $70^{\circ}$ and $65^{\circ}$ invariant correspond to electron aurora, while the sharp step increase in question at $60.8^{\circ}$ is entirely due to protons. At $58.2^{\circ}$ invariant there is a more gradual decrease in $\Delta B$, and at $56.1^{\circ}$ a brief rise and a very rapid decrease to the baseline value. The location marks a change in the proton angular distribution from isotropic to trapped. The significance of the $\Delta B$ decrease at $58.2^{\circ}$ in terms of the protons is not so evident, but it does appear to divide the region of isotropic protons into two parts. In the poleward part the proton flux decreases with decreasing invariant latitude and in the equatorward part the flux remains constant.

The electron temperature, obtained from the cylindrical electrostatic probe (CEP) is shown in the next frame above. Throughout the region of isotropic protons the electron temperature exceeds its background value of $4000 \mathrm{~K}$, rising to values above $8000 \mathrm{~K}$, in several well defined peaks. The first of these is close (electron temperature values are obtained once every $6 \mathrm{~s}$ ) to the upward field aligned current, the second and highest $T_{e}$ peak is located near the first downward current (dividing the two regions of isotropic protons) and the last one $(6000 \mathrm{~K})$ is located at the most equatorward downward current. The close correspondence between $T_{e}$ and the proton flux suggests that the protons are the energy source responsible for the electron heating, which presumably occurs elsewhere and is seen at the ISIS-II $1400 \mathrm{~km}$ altitude through heat conduction.

The next frame above shows vertical contours of constant electron density as measured by the topside sounder, from $1400 \mathrm{~km}$ down to the dashed line, beyond which the ionograms cannot be traced. It is seen that the location of the poleward fieldaligned current is associated with an increase of the topside electron density that continues to the first downward current, followed by a deep trough, extending down to $500 \mathrm{~km}$ at least, located at the more equatorward downward current which marks the equatorward boundary of isotropic protons. The initial increase in density at $61^{\circ}$ invariant can be seen within an ionogram, and occurs in a distance of about $5 \mathrm{~km}$.

The next frame above shows the ion densities (Hoffman et al., 1974) measured by the ion mass spectrometer (IMS) at the spacecraft, for the ions $\mathrm{O}^{+}, \mathrm{N}^{+}, \mathrm{He}^{+}$and $\mathrm{H}^{+}$. Note that the $\mathrm{O}^{+}$density scale (on the left) is compressed by a factor of 10 compared to that for the other ions, so that it is dominant by roughly that factor over $\mathrm{N}^{+}$, the next most important ion, and over $\mathrm{H}^{+}$by a factor of 60 at higher latitudes, with a sharp transition to a ratio of 20 at lower latitudes near the end of the data sequence. There is a remarkable peak in the $\mathrm{O}^{+}$ distribution centred near $57.5^{\circ}$, corresponding to the downward field-aligned current there, and coinciding with the increased topside density seen by the sounder. The upward step in $\mathrm{H}^{+}$at about $54.4^{\circ}$ invariant is normally taken to be an indicator of the plasmapause position (Chappell, 1972), located about $1.7^{\circ}$ beyond the equatorward proton boundary and the most equatorward field-aligned current (note however a later discussion of this plasmapause identification).

The topmost frame shows vertical contours of $6300 \AA$ volume emission rate. In cartwheel mode the $6300 \AA$ photometer views the same optical feature (in this case the SAR arc) many times from different angles. An image reconstruction technique developed by Stathopoulos and McConnell (1977) has been used to invert the data of Shepherd et al. (1976) to volume emission rates [for another example using a different technique see Hays et al. (1978)]. Only the data corresponding to the SAR arc were employed, with the background emission subtracted off prior to inversion. The SAR arc intensity maximum is located at $285 \mathrm{~km}$ and $05: 57 / 50$ U.T., coinciding closely with the upward field-aligned current. It appears to have a second component displaced to higher latitude, centred near $400 \mathrm{~km}$, and located at 05:57/40.

\section{A DETAILED EXAMINATION OF SOME FEATURES}

Much of the data shown in Fig. 1 are available only once per spacecraft rotation (18 s) or at comparable rates. But for some instruments a higher resolution data yield is possible. Figure 2 shows these data for the interval from $05: 57 / 35$ to 60 , 


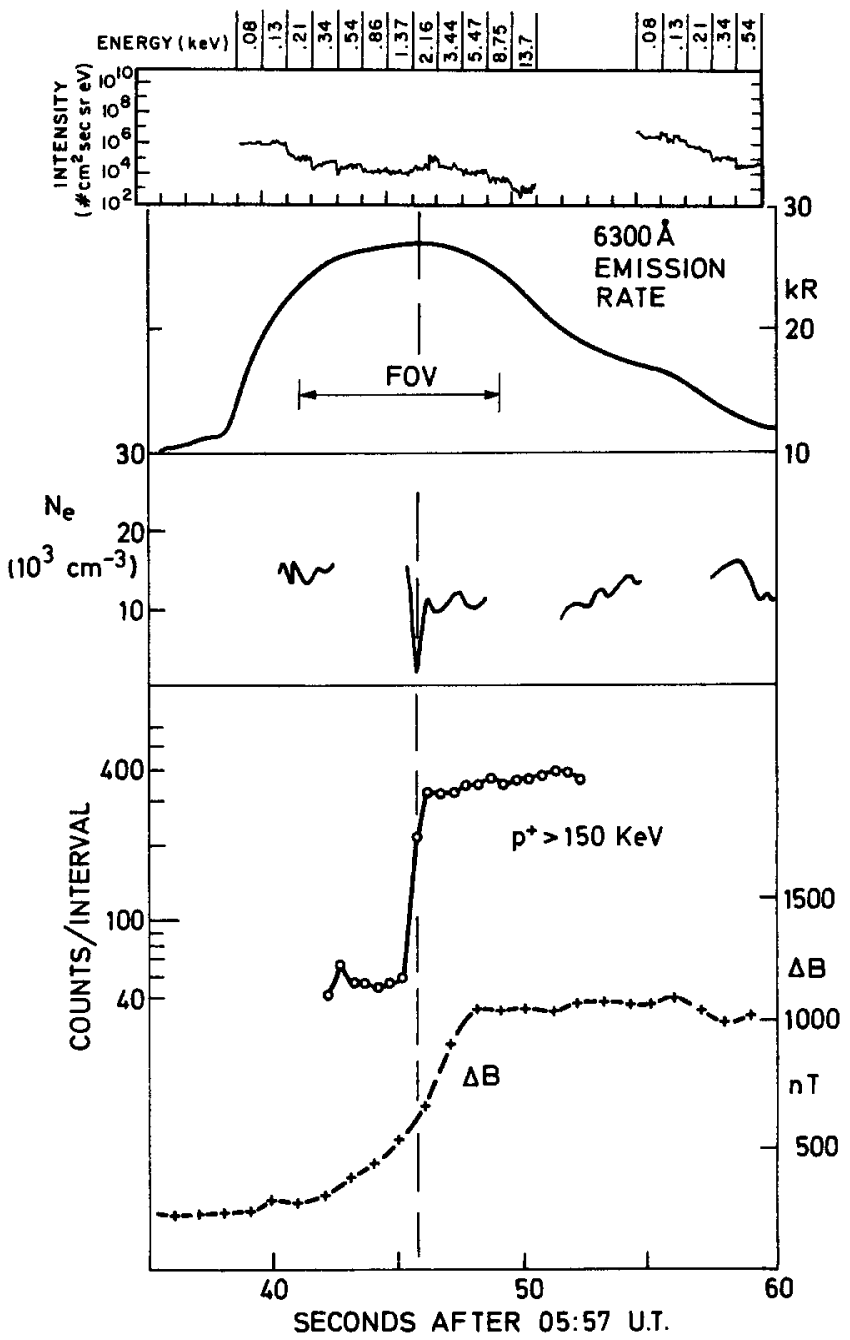

Fig. 2. High RESOlution Plot OF SELECTEd data fOR THE INTERVAL $05: 57 / 35$ TO $05: 57 / 60$, BRACKETING THE

SAR ARC AND THE UPWARD FIELD-ALIGNED CURRENT.

From top to bottom the frames are: soft particle spectrometer (SPS) measured electron energy fluxes, in a slow stepping mode, with the energy steps indicated above; $6300 \AA$ zenithal emission rate with the instrument fieldof-view indicated; electron densities at the spacecraft, proton count rate for $E>150 \mathrm{keV}$, and the $\mathrm{E}-\mathrm{W}$ component of magnetic perturbation.

spanning the region of the upward field-aligned current and the SAR arc. In the bottom frame a portion of the $\Delta B$ curve is shown, which has been smoothed with a 5-s filter as part of the normal data processing. The trace above this displays the proton data, for which the detector was fortunately scanning the upper atmosphere at the time, so that the step increase is entirely due to a change in proton flux. The CEP is kept at a fixed potential for about $3.5 \mathrm{~s}$ during its $6 \mathrm{~s}$ sweep, during which an electron density record is available at 120 samples $\mathrm{s}^{-1}$. These high resolution data segments are shown in the next frame above. Right at the proton boundary there is a deep and narrow depression (a slot) in the electron density, which drops from $15,00 \mathrm{~cm}^{-3}$ to $800 \mathrm{~cm}^{-3}$ over a region about $3 \mathrm{~km}$ wide altogether, and having a half-width of about $1.5 \mathrm{~km}$. A topside ionogram obtained at $05: 57 / 35$ contains a diffuse echo from this unusual feature but does not provide any further information about it. Another echo that presumably was from this feature was detected at $58 / 00$, with a horizontal range of $140 \mathrm{~km}$. The frame above this contains a portion of the $6300 \AA$ zenithal emission rate record, which yields one data point every $2 \mathrm{~s}$. The arrow indicates the field-of-view width of the photometer, which clearly determines the apparent width of the emission. The vertical line drawn at 57/45.7 appears centred on each of these phenomena to within about $1 \mathrm{~s}$, or better. In the top frame the instantaneous electron fluxes measured with the soft particle spectrometer (SPS) are shown. As explained in more detail below, the instrument was in a slow stepping mode for this pass, and at $46.2 \mathrm{~s}$ there was a factor-of-ten flux increase while the SPS was sitting at an energy of $2.16 \mathrm{keV}$. This time displacement of $0.5 \mathrm{~s}$ from the other events is puzzling.

The soft particle spectrometer (SPS) measurements are critically important. Their interpretation is made difficult by the very limited nature of the measurements that may be obtained by a single detector. The instrument provides detailed data about an incredibly small part of the multiparameter distribution function needed to completely specify the charged particle environment. During this particular orbit the device was in an energy stepping mode, dwelling at one energy step each second and making alternate electron and proton intensity measurements each $\frac{1}{60} \mathrm{~s}$. Thus, very high space/time resolution (30 samples/s/species) data are obtained at a given energy and pitch angle, but without knowledge of the fluxes at other energies and pitch angles. The energy flux versus time, averaged over $0.25 \mathrm{~s}$ intervals is shown in Fig. 3 . The instantaneous pitch angle of the particles observed is also plotted, and their energy in $\mathrm{eV}$ is written below for each $1 \mathrm{~s}$ interval. At 57/46.3 a sudden factor of ten increase is observed in the electron flux while the instrument is sampling electrons of $2.1 \mathrm{keV}$ energy at pitch angles near $50^{\circ}$. It should be pointed out that at $1400 \mathrm{~km}$, particles with pitch angles of $52^{\circ}$ will mirror at $300 \mathrm{~km}$, the 


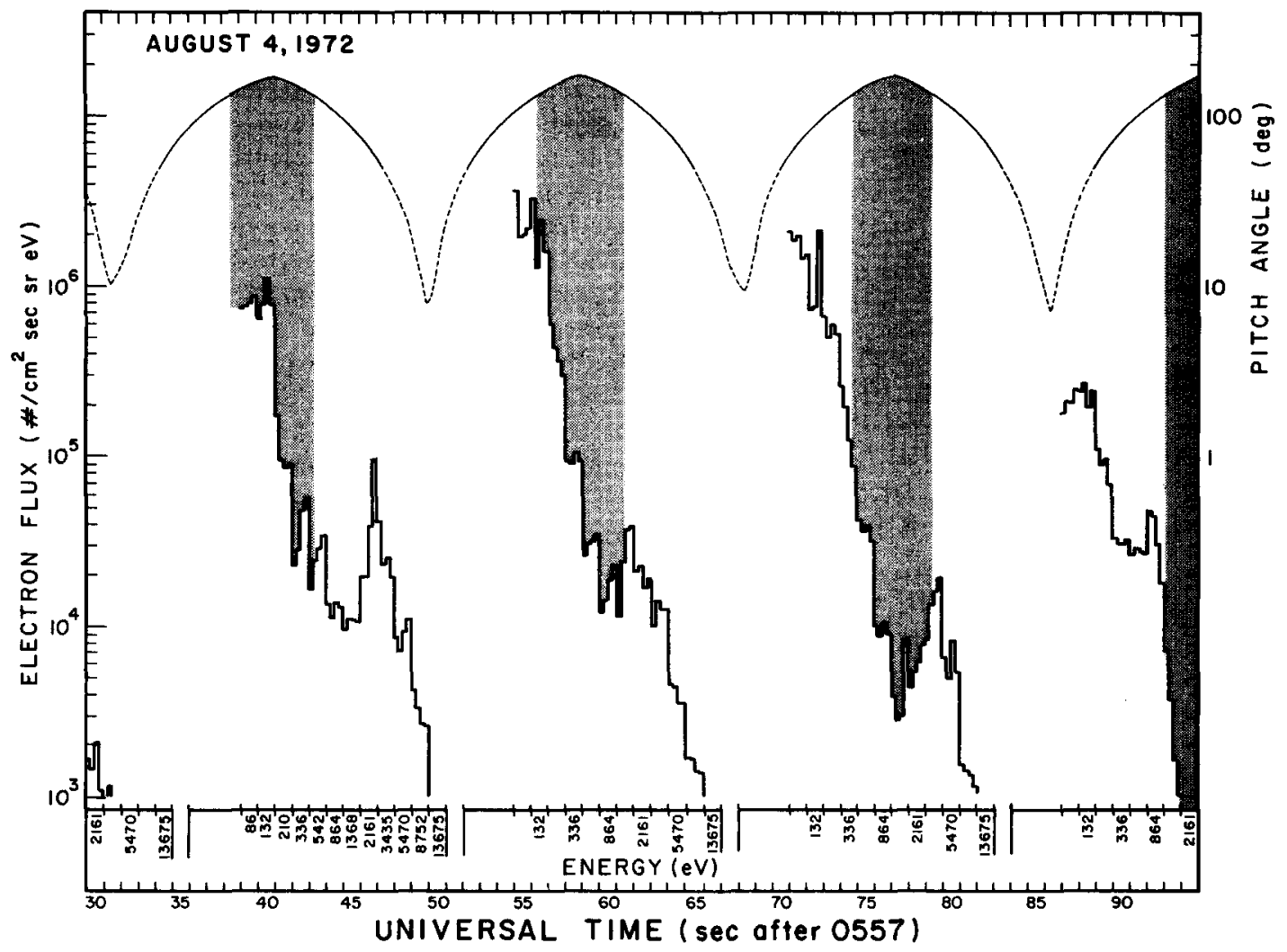

Fig. 3. Electron fluXes MEASUREd WTTH THE SPS IN A SLOW STEPPING MODE; THE ENERGIES ARE INDICATED BELOW.

altitude at which the maximum $6300 \AA$ emission rate is observed (Fig. 1). This dramatic increase occurs about $1 \mathrm{~s}$ later than the rise in proton flux, and the electron density slot, so is located about $7 \mathrm{~km}$ equatorward of these features. The flux decrease that immediately follows occurs after the instrument has stepped to the next energy so that it is attributed to a spatial/temporal variation and not to the energy spectral distribution. Shading in Fig. 3 indicates when the detector is looking downward at pitch angles greater than $130^{\circ}$ and seeing particles reflected from the atmosphere. The minima near 58/00 and 58/16 occur as the detector looks into the atmospheric backscatter loss cone, but the secondary maxima (e.g. at 58/02,58/18 and 58/32) show the presence of $1-2 \mathrm{keV}$ fluxes. The enhancements in electron flux at energies in the kilovolt range just outside of the backscatter loss cone probably represent the mirrored component of precipitating kilovolt electrons not seen because of the phasing between energy and pitch angle. Following each 15-s cycle of energy steps, a rapid reverse sweep occurs within the 16 th $\mathrm{s}$, permitting a meaningful energy spectral distribution to be obtained.
Four of these spectra are shown in Fig. 4. The first is obtained at $05: 57 / 35$ at a pitch angle of $73^{\circ}$ (outside the loss cone) and shows a weak flux, monotonically decreasing with increasing energy above $5 \mathrm{eV}$ that probably arises largely from photoelectrons, with some indication of $1 \mathrm{keV}$ auroral electrons. The second spectrum, which at $57 / 51$ follows the first flux increase at 57/46, shows a factor of 60 increase in the $20 \mathrm{eV}$ flux, and a spectral shape above this energy that is similar to the first spectrum, but a factor of 10 higher in flux. This spectrum at a pitch angle of $31^{\circ}$ samples particles with mirror points deep in the atmosphere. In the next spectrum obtained at 58/07 at a pitch angle of $14^{\circ}$ the low energy component decreases somewhat while the $1 \mathrm{keV}$ flux changes relatively little. It should be noted that the two most intense spectra correspond to precipitating particles (i.e. mirror points deep in the atmosphere) while the low intensity spectra at $57 / 35$ and $58 / 23$ are due to particles with mirror points well above $450 \mathrm{~km}$.

Strong whistler-mode noise at frequencies between 0.1 and $0.4 \mathrm{MHz}$ was observed by the sounder 


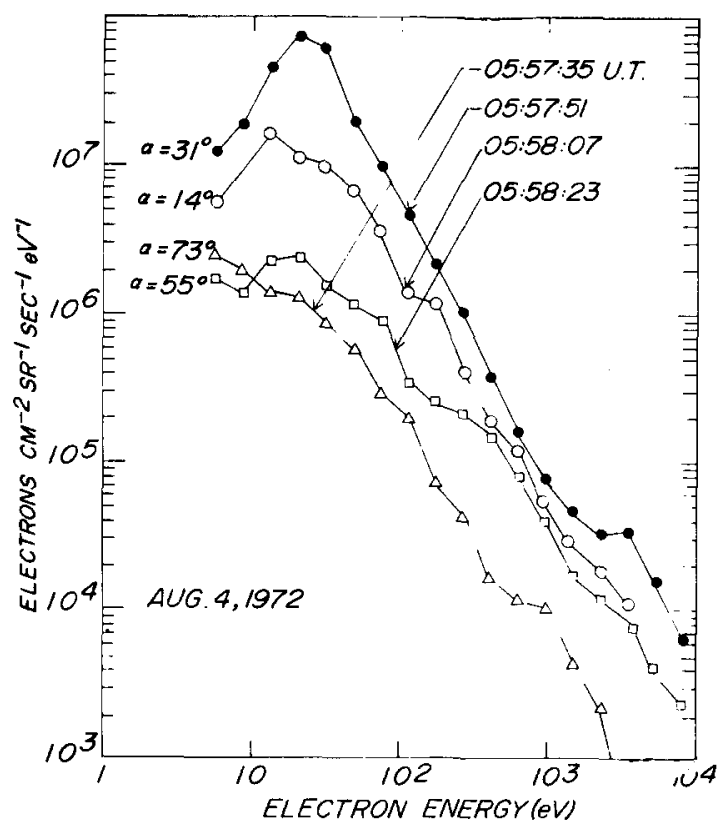

Fig. 4. DifFERENTIAL ELECTRON ENERGy SPACTRA $5 \mathrm{eV}$ TO $10 \mathrm{keV}$, MEASURED WITH THE SPS DURING ITS RAPID REVERSE SWEEP, AT THE FOUR TIMES INDICATED, WITH THE CORRESPONDING PITCH ANGLES SHOWN $(\alpha)$.

receiver during a short interval centred near $05: 57 / 30$, as shown in the bottom frame of Fig. 1 . The peak wave spectral power density of about $5 \times 10^{-17} \mathrm{~W} \mathrm{~m}^{-2} \mathrm{~Hz}^{-1}$ is comparable to levels reported elsewhere (see references in Maggs, 1976) for strong events in the auroral oval. The individual spectra exhibit sharp upper frequency limits well below both the electron plasma and gyrofrequencies, at about $400 \mathrm{kHz}$. Such a spectral shape is quite different from what is predicted by the linear amplification model of Maggs (1976, and private communication) when the observed electron fluxes and ambient parameters are applied. Furthermore the spatial cutoffs of the noise between $56 / 48$ and $57 / 10$ and between $57 / 56$ and 58/18 appear much sharper than would be expected on the basis of space-frequency selectivity of the beam-plasma instability mechanism (Maggs, 1976) or of geometrical factors such as discussed by James (1973). The fast drop-off is regarded as a true spatial effect and not a time variation in view of the colocation of the noise with the particle precipitation and $6300 \AA$ emission. Instability growth lengths are calculated to be of the order of kilometers in the present conditions. All of these facts lead to the interpretation that between $57 / 10$ and $57 / 56$ the satellite is inside a beam which has created very short wavelength waves that have grown to some non- linear level of amplification. Such waves would exist only inside the exciting beam volume; outside they would be quickly Landau damped as they attempted to propagate away.

If the whistler-mode oscillations in the beam have been amplified to nonlinear levels, this mechanism may be able to transfer precipitating flux energy to the ambient medium via turbulence. The fluctuations in $n_{e}$ and $T_{e}$ observed near $61^{\circ}$ invariant latitude may be caused in part by such turbulence, in addition to the usual $F$-region collisional processes. A strong beam-plasma interaction would alter the beam electron distribution throughout its operative height range which probably extends hundreds of kilometers above and below the satellite, tending to produce a spectrum that is monotonically decreasing with energy. That is, at $F$-layer altitudes and below, the electron flux spectrum causing optical emissions and changes in thermodynamic parameters would be different from that observed at ISIS-II. Unfortunately, the only way to calculate this is by costly numeric simulation.

We consider now the energy spectra of the electrons and protons at higher energies, as determined by the EPD. Figure 5 shows integral electron

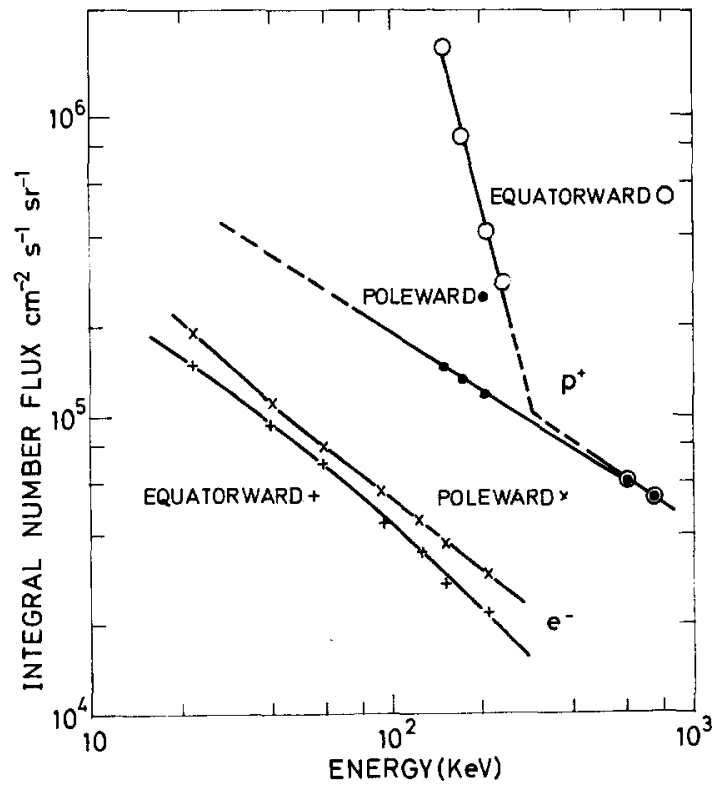

FIG. 5. INTEGRAL ELECTRON SPECTRA (20-200 keV) AND PROTON SPECTRA $(150-700 \mathrm{keV})$ OBTAINED WITH THE EPD, ON THE EQUATORWARD (05:56/58-57/00) AND THE POLEWARD $(05: 57 / 46-57 / 54)$ SIDES OF THE SAR ARC.

The pitch angles are in the range $70-110^{\circ}$ but the fluxes are isotropic in any case. 
spectra above $20 \mathrm{keV}$, and proton spectra above $150 \mathrm{keV}$ obtained poleward and equatorward of the SAR arc. These were measured by integral detectors, assuming power law spectral shapes. The poleward proton influx is substantial, and exceeds the electron number flux at the same energy. The data shown are for mirroring particles but the angular distributions are essentially isotropic here. These fluxes have the appearance of solar electrons and protons since the fluxes and spectra are uniform from the SAR arc up to $74^{\circ}$ invariant, apart from the two electron acceleration regions at $64^{\circ}$ and $71^{\circ}$. The electron spectrum equatorward of the SAR arc has a slightly lower flux (or energy) than in the poleward region, while the proton spectrum is identical above $250 \mathrm{keV}$, but is drastically modified below that energy. The flux increase equatorward of the SAR arc increases with decreasing energy down to $150 \mathrm{keV}$, where the integral measurements terminate and where the flux enhancement is a factor of 12 . Other detector channels show that the proton flux enhancement extends down to $8 \mathrm{keV}$, where the increase is just detectable. The implication is that these are not direct solar protons and electrons but are inwardly diffusing protons and electrons that are uniform from $L=13.1\left(74^{\circ}\right)$ to $L=4.1$ where the protons are abruptly destabilized by some process. The electrons are unaffected, showing that electric field acceleration processes are not involved.

\section{GROUND-BASED ORSERVATIONS}

The spacecraft geographic longitude was $170^{\circ} \mathrm{E}$, passing near Campbell Island $\left(60^{\circ}\right.$ invariant $)$, which is located very close in latitude to the strong upward field-aligned current, and passing within $3^{\circ}$ longitude of Christchurch (50 invariant), where additional observations were made. Magnetograms were available from both Amberly (near Christchurch) and Campbell Island. Both show a sudden commencement near 01:20 UT, coinciding with the interplanetary shock observed by Smith et al. (1977), followed by a series of oscillations in all components with periods of roughly $20 \mathrm{~min}$, which continued for some hours and were still in progress at the time of the pass. The Island record was wildly varying at that time while the Amberly record shows more regular variations, but in neither case is it possible to relate these variations to the locations of the ionospheric currents that might be expected in association with the field-aligned currents. The much larger amplitudes at Campbell Island show that there is a localized effect and not just an overall magnetospheric oscillation, and one could interpret the pattern as a normal, but disturbed, nightside electrojet. This interpretation has some support in that there is $1-10 \mathrm{keV}$ precipitation present throughout the field-aligned current region, and in that auroral radar echoes having an equatorward boundary very close to the upward current were obtained from Slope Point. Unwin (1979) has shown that upward field-aligned currents are the site of diffuse radio auroral echoes. On the other hand it may well be that the radar echoes are associated with the energetic precipitation and the field-aligned current with the low energy precipitation, or even with both. Since the poleward boundaries of the protons, the low energy electrons and the energetic electrons coincide so closely it is impossible to be sure.

The riometer at Campbell Island detected the beginning of an absorption event at about $04: 17$, and at 07:00 U.T. it was in a slow decline that continued to about $08 \mathrm{~h}$. The ionosonde there showed a complete blackout, with the last $F$-region echoes disappearing about $1 \mathrm{~h}$ before the pass These effects were presumably associated with the energetic electron precipitation. The Christchurch ionogram at $05: 30$ showed an oblique trace at a range of $850 \mathrm{~km}$ which remained as a fuzzy remnant at $06: 00$. At $06: 15$ there was a very unusual and curious re-entrant trace that suggests the existence of a tilted ionosphere; that is, with a strong horizontal density gradient. This kind of trace is sometimes seen in connection with travelling ionospheric disturbances.

Unfortunately no optical data were available from New Zealand because of cloud. However some of the features are reminiscent of an event that occurred at Saskatoon, Canada, also at $60.5^{\circ}$ invariant, and also at dusk, at 00:40 U.T. on 16 November 1960 . This observation was reported upon by Shepherd (1965) at the same SAR arc meeting at which Cole presented his original theoretical model. The patrol spectrograph results from Saskatoon showed a normal auroral feature overhead, and a very much enhanced $6300 \AA$ feature just south of the zenith. The $5577 \AA$ emission and $\mathrm{N}_{2}{ }^{+}$bands were weakly evident in the same form, indicating the presence of some energetic precipitation as well. The all-sky camera showed a band coming from the west that appeared overhead as a narrow sheet. Thus as for the 4 August 1972 arc, this one would appear narrow and very red enhanced.

Weber et al. (1976) have reported upon the intensity patterns of the $\mathrm{N}_{2}{ }^{+}(4278 \AA)$, OI $6300 \AA$ 
and H-beta ( $4861 \AA$ ) emissions at the south pole during this storm. They observed a relatively hard electron precipitation event at $03 \mathrm{~h}$ on 4 August and a softer event beginning at or soon after 06:00 U.T. The first major proton induced emission did not appear until after 10:30 U.T.

\section{INTERPRETATION}

It is important to determine whether the physical effects described can explain the excitation of the SAR arc emission observed. The SPS spectrum at $05: 57 / 51$ was used as input to the energy degredation model of Banks et al. (1974), along with the topside sounder electron density profile, and this yielded the vertical emission rate profiles of Fig. 6, calculated for both a "hot" and a "cold" atmosphere. The integrated emission rate is about $2.2 \mathrm{kR}$ and the peak volume emission rate is at $340 \mathrm{~km}$. The calculation included only electron impact excitation and used the quenching rate for $\mathrm{O}\left({ }^{1} \mathrm{D}\right)$ by $\mathrm{N}_{2}$ of $2 \times 10^{-11} \mathrm{~cm}^{6} \mathrm{~s}^{-1}$ given by Torr et al. (1975). The measured volume emission rate profile as extracted from the tomographic inversion is shown as well, and it displays a double-peaked distribution. The lower peak agrees well in altitude with the predicted one, with the predicted rate a factor of two lower than that observed, which is probably within the inherent errors of the comparison. The observed higher altitude component, with its peak near $400 \mathrm{~km}$ cannot be explained by this source. One explanation is that the electron energy spec- trum was spatially rapidly changing, and that at $57 / 45$ it contained a low energy component that was not measured at $57 / 51$. The sharp rise in the electron flux at $57 / 45$ does suggest that something significant did occur then. But this is a somewhat arbitrary explanation and ignores the fact that the agreement for the low altitude region is as good as it is. A more plausible interpretation is that the upper component was excited through the generally accepted SAR arc mechanism (Rees and Roble, 1975), of heat conduction through the electron gas, which is known to provide peak excitation at about $400 \mathrm{~km}$. From the models provided by Rees and Roble (1975) we selected model 7 as closest in electron density $\left(1.5 \times 10^{4} \mathrm{~cm}^{-3}\right)$ and electron temperature $(8000 \mathrm{~K})$ to the values observed here at $1400 \mathrm{~km}$. This model predicts an integrated intensity of $5.5 \mathrm{kR}$, close to the integrated intensity above $350 \mathrm{~km}$ of $4.7 \mathrm{kR}$ that was observed. The input heat flux required for this model is $10^{11} \mathrm{ev} \mathrm{cm}^{-2} \mathrm{~s}^{-1}$. The remainder of the interpretation is developed on the concept of the "twocomponent" SAR arc, having a soft electron excited component, and a thermally excited component. A further question arises as to whether these two components are related, or are essentially independent. The whistler mode noise that was observed to be centred on the thermal component implied non-linear levels of wave growth, which may have allowed electron beam energy to be transferred to the plasma, and so might provide a natural explanation for the thermal excitation.

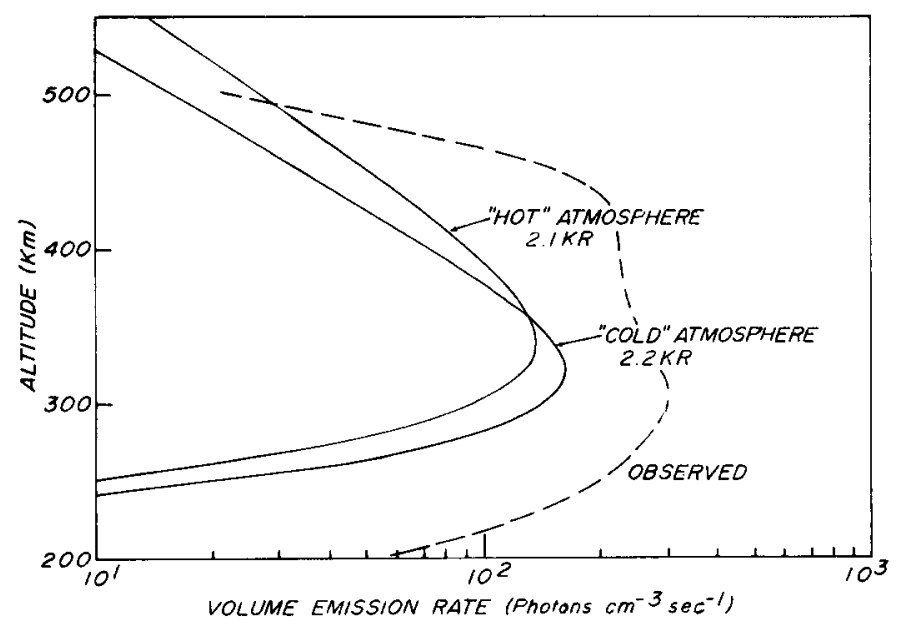

FIG. 6. $6300 \AA$ VOLUME EMISSION RATES CALCULATED FOR THE CONDITIONS OF THIS SAR ARC, EXCITED BY ELECTRON IMPACT WITH THE 05:57/51 SPECTRUM OF FIG. 4, USING THE BANKS et al. (1974) PROCEDURE.

Results are shown for a "hot" and a "cold" atmosphere, and compared with the observations derived from Fig. 1. 
However, there is no way to verify this at the present time.

We next consider the relationship of the soft electron flux, the field-aligned current and the electron density "slot." As shown, these phenomena have the same location within the experimental error of the measurements, and it seems reasonable to assume that this was not the result of chance. The field-aligned current carried by the SPS electrons measured at 51/51 cannot be calculated precisely because of the poor knowledge of the angular distribution. However, if we integrate over the electron energy spectrum measured then, which has a peak flux of $8 \times 10^{7}$ electron $\mathrm{cm}^{-2} \mathrm{sr}^{-1}$ $\mathrm{s}^{-1} \mathrm{eV}^{-1}$ and assume that the distribution is isotropic, we calculate a current density of $10 \mu \mathrm{amp}$ $\mathrm{m}^{-2}$, compared with the magnetometer measured value of $14.5 \mu \mathrm{amp} \mathrm{m^{-2 }}$. It seems plausible that the soft electrons are the current carriers involved, which requires that there not be a significant flux of electrons returning up the same field line. This conclusion also implies that there is no current associated with the thermal excitation, so that it is a true heat flux and not an electron flux. The "slot" of electron density depletion observed in this same location would also seem to be related to the field-aligned current. It is not possible to understand this depletion in terms of the processes described by Block and Fälthammar (1968), who show that such a strong depletion would be best explained by upward ion flow in the topside ionosphere. The downward electron flow observed here would, with their model, predict a topside electron density enhancement instead. However, the "slot" is only about $1.5 \mathrm{~km}$ in half-width, and none of the other measurements were made with sufficient time resolution to see variations over this spatial scale. The failure to see evidence for these processes most likely results from the fact that the relevant data on ion and electron flows on this spatial scale are just not available. The large-scale depletion observed at the equatorward proton boundary can be understood in terms of topside upward electron flow as described in the Block and Fälthammar (1968) model, which is consistent with the downward fieldaligned current observed there. The $\mathrm{O}^{+}$enhancement at $57.5^{\circ}$ invariant may possibly be explained from their model as arising from topside downward electron flow, which must be associated with upward ion flow near the $F$-region peak, that could produce the $\mathrm{O}^{+}$enhancement seen at $1400 \mathrm{~km}$.

We next consider the possible role of the proton boundary in these processes. Cole (1965) originally proposed that SAR arcs were produced by
Coulomb collisions between the ring current protons and the electron gas, accompanied by heat conduction to ionospheric levels where thermal excitation of the $\mathrm{O}\left({ }^{1} \mathrm{D}\right)$ state would occur. Cornwall $e$ al. (1971) pointed out that while this works well at proton energies of a few $\mathrm{keV}$, that at ring current energies ion cyclotron resonance accompanied by electron Landau damping would be a more important process. However, the final identification of which is the more important process has not yet been resolved. A related question is to what extent these processes, which are equivalent to proton precipitation loss, dominate over the loss of ring current protons through charge exchange with atmospheric neutral hydrogen. A recent analysis by Tinsley (1976) of the charge exchange lifetime for $50 \mathrm{keV}$ protons at $L=4$ gave a value of $20 \mathrm{~h}$, while for $\mathrm{He}^{+}$ions of the same energy the lifetime was $29 \mathrm{~h}$. At $10 \mathrm{keV}$ the difference in lifetime is very dramatic, 4.6 and $166 \mathrm{~h}$ for $\mathrm{H}^{+}$and $\mathrm{He}^{+}$respectively. On these grounds Tinsley (1976) proposed that the recovery phase ring current was not composed of protons, but some heavier ion, probably $\mathrm{He}^{+}$. A different kind of experimental evidence supporting this view was put forward by Lyons and Evans (1976). On the other hand, ring current observations by Smith et al. (1976) found charge exchange by ring current protons to be consistent with the decay times they observed. Indirect measurements by Blake (1976) indicated that protons were absent in late recovery but direct measurements by Sharp et al. (1976) during the December 1971 storm found both $\mathrm{H}^{+}$and $\mathrm{O}^{+}$to be present while $\mathrm{He}^{+}$was absent. Further, the latter authors concluded that ion cyclotron resonance and charge exchange were equally important loss mechanisms. Williams and Lyons (1974a, b) had earlier put forward evidence from proton angular distributions for the ion cyclotron resonance process and Taylor and Lyons (1976) and Kintner and Gurnett (1977) had both observed ion cyclotron waves in association with times of enhanced $D_{s t}$, but without proving that this resonance process was the dominant mechanism. At the present time one can only conclude that the process as regards ring current composition and energy loss, including those which excite SAR arcs, are complex, that more than one process may be involved in a given event, and their relationship may be different in different events. For the SAR arc under investigation here it seems likely that the heavy ions were protons, as $\mathrm{O}^{+}$ions would imply a much higher energy for the detector involved. In addition, these observations were made during the growth of the storm and not its 
recovery. It may be that proton excitation was one of the unusual aspects of the excitation of this arc, while the SAR arcs generally observed during recovery phase might be generated by $\mathrm{O}^{+}$remaining after the protons have decayed.

To attempt to identify the energy flow processes involved in this SAR arc we make use of observations from the near-equatorial Explorer $45\left(S^{3}-A\right)$ spacecraft (Hoffman et al., 1975), made during the same time period. At $06 \mathrm{~h}$ U.T. on 4 August, their observations placed the plasmapause at $L=4.2$ $\left(60.8^{\circ}\right.$ invariant $)$; the spacecraft was outward bound through the noon sector at this time. This does not agree with the ISIS-II observations of the low altitude plasmapause, manifested by the $\mathrm{H}^{+}$step, shown in Fig. 1 at $54^{\circ}$ invariant. However, recent results by Foster et al. (1978) show that the light ion boundary observed by ISIS-II is generally 2 $10^{\circ}$ equatorward of the equatorial plasmapause as determined by VLF measurements. We may therefore consider it likely that the SAR arc was located near the equatorial plasmapause. A few hours later the $\mathbf{S}^{3}$-A spacecraft observed ring current protons on its inbound pass through the dusk sector, with an energy density a factor of two higher than on the previous orbit and at $L=4$, higher than observed on any subsequent orbit during this storm. Even so, this density was a factor of 1.5 less than the peak densities observed during the 18 December 1971 and 17 June 1972 storms. The peak density at $L=4$ for the 4 August storm was $4 \times 10^{-7} \mathrm{erg} \mathrm{cm}^{-3}$ (Hoffman et al., 1975) and we now estimate the rate of precipitation loss. For particles mirroring at the $1400 \mathrm{~km}$ ISIS-II altitude, the related equatorial solid angle is $5 \times 10^{-2} \mathrm{sr}$ and if diffusion into the loss cone were very fast, the fraction $f=$ $5 \times 10^{-2} / 4 \pi$ could be lost in one hemisphere for every bounce period. If we imagine that the proton source region occupied a length $d$ along the field line then the total energy loss rate $E$ is $E=w f d / t_{b}$, where $w$ is the energy density and $t_{b}$ is the bounce time. Since the bounce time is related to the source length through the particle velocity, $v$, the source length cancels and the energy loss rate is $E=w f v$, which becomes $0.5 \mathrm{ergs} \mathrm{cm}^{-2} \mathrm{~s}^{-1}$ for $150 \mathrm{keV}$ protons as observed by ISIS-II. This equatorial loss flux may be multiplied by the magnetic field ratio to transform it to the flux at $1400 \mathrm{~km}$, yielding $32 \mathrm{erg} \mathrm{cm}^{-2} \mathrm{~s}^{-1}$, compared with the value $0.5 \mathrm{erg} \mathrm{cm}^{-2} \mathrm{~s}^{-1}$ observed there. This indicates that the energy source observed by $S^{3}-A$ is ample for ISIS, but also shows that the diffusion rate into the loss cone is a factor of 64 less than the maximum possible rate. The equivalent lifetime of the ring current then comes out to be $4.5 \mathrm{~h}$, which is consistent with the previous discussion. The heat flow requirement for the SAR arc was earlier estimated to be $0.16 \mathrm{erg} \mathrm{cm}^{-2} \mathrm{~s}^{-1}$, and the soft electrons carried a similar energy; the sum is comparable to that carried by the precipitating protons. Since this is much less than the source fast diffusion rate, the proton energy source is adequate to drive the SAR arc, but this information is still insufficient for us to conclude that the protons are the actual energy source for the soft electrons, the thermal component, or both.

To pursue this question we now consider the proton/electron energy transfer mechanism in more detail, considering at the same time whether any of the possible mechanisms could excite electrons to energies of $20 \mathrm{eV}$ or so. It seems unlikely that Coulomb collisions could provide these energies, without at the same time raising the ionospheric electron temperature to the same level. Hawegawa and Mima (1978) point out a potentially serious limitation of the processes we have so far discussed, arising in the relationship of the electron-electron collision time $t_{c}$ to the electron bounce time $t_{b}$. For $T=1 \mathrm{eV}$ and $N_{e}=10^{3} \mathrm{~cm}^{3}$ these times are equal. But with increasing electron temperature $T$ the ratio $t_{c} / t_{b}$ increases as $T^{2}$. This means that as electron heating proceeds the electrons come quickly into a collisionless regime in which they are simply trapped near the equator so that the electron energy can only be lost through precipitation. One might expect that under certain conditions that the temperature of these trapped electrons could rise to very high values, but the Landau damping associated with the ion cyclotron resonance mechanism limits the electron velocity to the Alfvén velocity and this provides a natural energy bound. Even so, the model of Cornwall et al. (1971) (their Fig. 5) shows that to produce the heat flux of $10^{11} \mathrm{eV}$ $\mathrm{cm}^{-2} \mathrm{~s}^{-1}$ required here would imply electron energies at the equator of $5 \mathrm{eV}$, which is not all that far from the $20 \mathrm{eV}$ observed. An interesting mechanism for SAR arcs has recently been put forward by Hasegawa and Mima (1978). They show that shear Alfvén waves can accelerate electrons longitudinally through Cerenkov resonance in a mode they call the kinetic Alfvén wave. The scale size of this process is that of the MHD wavelength along the fieldline, which is comparable to the fieldline length, and this overcomes the trapping problems of the earlier mechanisms described, where the scale sizes are much shorter. Lanzerotti et al. (1978) apply this theory to ground-based hydromagnetic wave observations during the De- 
cember 1971 event to show that adequate energy can be delivered by this mechanism to excite a SAR arc.

The kinetic Alfvén wave is accompanied by a parallel electric field which produces an additional electron-wave interaction, leading to dissipation of field-aligned current through anomalous resistivity. This mechanism therefore seems to offer the possibility of explaining the field-aligned current and the low energy electron excited component. It might also explain the thermal component as part of the same process, but this component could be produced independently by either the Coulomb collision or the ion cyclotron resonance process. In any case the coincidence of the two components would not be accidental, but related through the physical processes. An important aspect of the ISIS-II observations is that the precipitating ring current protons are present over a rather wide latitude region, throughout which the electron temperature shows four distinct peaks at $1400 \mathrm{~km}$, while the $6300 \AA$ emission appears strongly at only one of them, the most poleward peak lying at the poleward proton boundary. This indicates that different processes of the type described above may be operating in different regions, possibly producing some $6300 \AA$ emission which was not detectable under these twilight conditions, while the specific process operating at the poleward boundary produced the narrow intense feature that has been described.

An entirely different explanation for this $6300 \AA$ feature is that it was in fact aurora, in which case some auroral-type mechanism can be invoked. With this view the magnetospheric electric field provides the driving mechanism. This field maps down in the ionosphere to spacecraft times corresponding to $56 / 00$ on the poleward side down to $59 / 25$ on the equatorward side. Ionizing fluxes of solar protons and electrons exist at all latitudes poleward of $59 / 25$, providing enhanced conductivity. The auroral radar data indicate that the ionospheric electric field is strong enough to excite the two-stream instability in this evening region of Pederson currents linking the regions of downward and upward field-aligned current flow. Additional acceleration processes excite the keV electrons observed. The sharpness of the proton boundary and the abruptness of the conductivity discontinuity there causes a high density field-aligned current. Anomalous resistivity which develops on account of the high current density leads to potential drops and the precipitation of low energy electrons of about $20 \mathrm{eV}$. The high temperatures are caused by Joule heating associated with the Pederson cur- rents. In this scenario the protons play a secondary role, in providing only the conductivity discontinuity necessary to stimulate the field-aligned current. While the data presented here appear inadequate to definitely accept or reject the "ring current model" or the "auroral model," we prefer the model in which the protons themselves provide the fundamental energy source. The "auroral model" does not imply any very unusual circumstances, whereas the optical event described is extremely unusual. It is in fact unique to the ISIS data so far examined, and does not correspond to any events described in the literature, by ground-based or other means. Further, in the auroral model one must say that the superposition of this sharp proton boundary upon what were otherwise normal auroral conditions was purely a coincidence. In the ring current model one regards the location of the protons as a fundamental matter and not a result of chance. In our view this phenomenon could not be the more unusual Type A aurora either. During the 18 December 1971 storm Bunn and Shepherd (1979) found the occurrence of Type A aurora to be very widespread, essentially filling the polar cap. The SAR arc observed during that storm (Maier et al. 1975) was quite distinct from the auroras observed at the same time.

\section{COMPARISON WITH ANOTHER SAR ARC EVENT}

For comparison with ISIS-II data taken under similar conditions but for a more normal SAR arc, the period of the ring current observations of Berko et al. (1975) was selected. The ISIS-II results for 18 June 1972 are shown in Fig. 7 in a format similar to that of Fig. 1. (The time scale runs in the opposite direction so that the latitude scales have the same direction.) In the bottom frame, starting on the right, one sees a uniform airglow intensity of about $500 \mathrm{R}$ from $1: 25$ to $1: 27 / 30$ and then at $1: 28$ a $1 \mathrm{kR}$ peak labelled SAR arc, followed at $1: 29$ by a rapid rise as the auroral region is entered. The $5577 \AA$ emission is shown as a broken line which has an airglow value of about $200 \mathrm{R}$, shows essentially no response to the SAR arc, and rises rapidly at the equatorward auroral boundary. Anisotropic (trapped) protons are evident over the range indicated, with a sharp equatorward boundary, and a more gradual poleward boundary. The axial magnetometer deviation is shown in the same frame; there is no evident response to the SAR arc. A slight downward shift in the region of the protons can be seen but its validity is uncertain. The large auroral response is obvious. The middle 


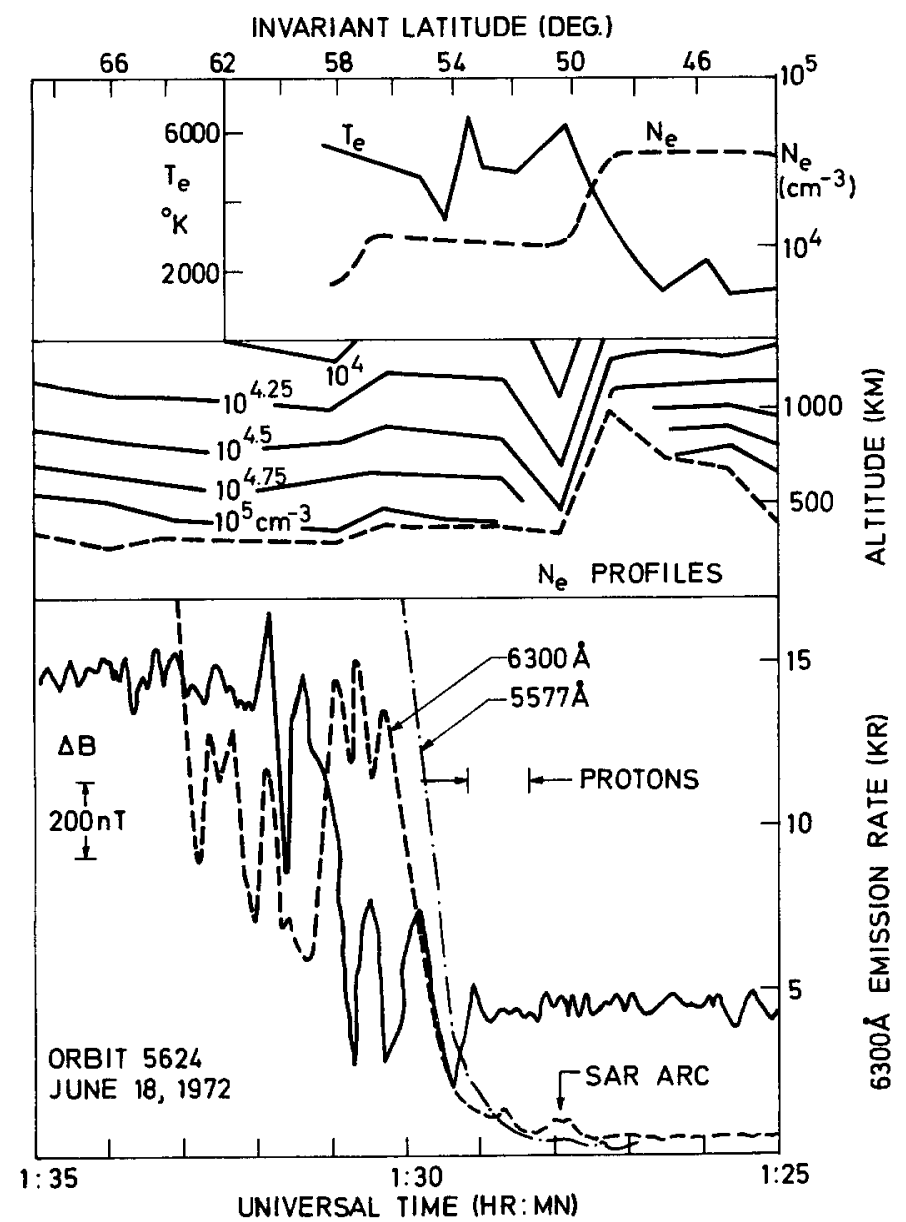

FIG. 7. ISIS-II DATA FOR A "NORMAL" SAR ARC, OBSERVED 18 JUNE 1972.

The format is similar to that of Fig. 1. In this case the SAR arc (indicated) is a very weak feature compared with the nearby aurora.

frame shows the vertical profiles of electron density. There is a marked topside trough, located very close to the SAR arc location. The top frame shows the electron density at the spacecraft measured with the CEP, and displays a marked step at the middle of the trough, that would formerly have been taken as the low altitude plasmapause. There is an electron temperature peak of $6000 \mathrm{~K}$ in the trough region, and a similar peak located at the poleward proton boundary. The SPS spectrogram is not shown, but there is no evidence of soft electron precipitation at the SAR arc.

Compared with the 4 August 1972 SAR arc this one has a similar flux of protons, but trapped rather than precipitating, similar electron temperature values, and a similar topside electron density trough at the equatorward proton boundary. The 18 June SAR arc is located in this trough, rather than the poleward boundary, and is 20 times lower in intensity. The $\Delta B$ for the 4 August event was $800 \mathrm{nT}$, so a simple proportionality would yield $40 \mathrm{nT}$ for this one, which is comparable to the noise level, and consistent with the marginal deviation noted. The soft electron flux at the SAR arc is difficult to determine since there is some interference from the topside sounder. A flux of $10^{-3} \mathrm{erg} \mathrm{cm}^{-3} \mathrm{sr}^{-1} \mathrm{~s}^{-1}$ could be present and go undetected, corresponding to the factor-of-twenty scaled value of $8 \times 10^{-3}$. We therefore conclude that soft electrons, $E>5 \mathrm{eV}$ are not present in the 18 June SAR arc, at least not with proportional fluxes. It may be noted in the SPS data that the aurora associated with this SAR arc had a highly developed plasma sheet, with precipitating fluxes of $100 \mathrm{erg} \mathrm{cm}^{-2} \mathrm{sr}^{-1} \mathrm{~s}^{-1}$, while the plasma sheet was virtually absent for the 4 August event, which corresponded to a very weak 
auroral situation. Finally we note from Berko et al. (1975) that the symmetrical ring current, observed one day later, had an energy density of $6 \times$ $10^{-7} \mathrm{erg} \mathrm{cm}^{-3}, 50 \%$ higher than for the 4 August event.

We now turn to other observations in the literature. Norton and Findlay (1969) compared data from three Alouette passes for 29 September, 1967 with ground based SAR arc observations and found the SAR arcs very close to the $F$-region trough. Carpenter (1971) compared plasmapause locations obtained from VLF OGO 2 and OGO 4 data with ground-based SAR arc observations for the same event, and for the event of 1 November 1968 . He concluded that the SAR arc was located about $1^{\circ}$ equatorward of the plasmapause identified in this way. Chappell et al. (1971) compared the $\mathrm{H}^{+}$ion densities measured with OGO 5 and for the same 1 November 1968 event found the SAR arcs associated with the inbound and outbound crossings to be $7^{\circ}$ and $3^{\circ}$ poleward of a steep ion density gradient at $L=2$. These data are reproduced in a recent paper by Lundblad and Søraas (1978) along with electron temperature data by Raitt (1974) from ESRO 1A and their own ESRO 1A proton data. Lundblad and Søraas identify the SAR arcs with a peak in the $90^{\circ}$ proton fluxes $(150-215 \mathrm{keV}$, most predominantly) that relates well to the electron temperatures, but not to any distinguishing feature in the $\mathrm{H}^{+}$density, other than to a shallow gradient lying poleward of the plasmapause. In other passes Lundblad and Søraas (1978) find sharply defined $90^{\circ}$ proton enhancements lying above a smooth background that is always present. They attribute this enhancement to wave activity but it cannot be identified with a specific plasmapause associated feature. These observations are all consistent with the characteristics at the equatorward proton boundary of the 4 August event, where the $F$-region trough and an electron temperature enhancement are located at the boundary between isotropic and trapped protons. That these lie about $2.5^{\circ}$ poleward of a sharp low-altitude $\mathrm{H}^{+}$gradient is also consistent with the earlier discussion about relative equatorial and lowaltitude plasmapause locations.

Proton loss from the ring current may be studied as low-altitude precipitation, but it may also be studied at the equator as done by Williams and Lyons (1974a, 1974b). They show isotropic proton distributions near the equator and outside the plasmapause, with rounded pitch angle distribution peaked at $90^{\circ}$ as one approaches the plasmapause. In approaching the plasmapause from the poleward side the higher energy protons show the effect first. Their interpretation is that the rounding is caused by pitch angle diffusion initiated by the amplification of ion cyclotron waves in the interacting hot and cold plasmas. With this interpretation their data are consistent with a refilling of the plasmasphere during recovery. In a later paper, Williams et al. (1976) the proton energy loss rates are calculated as a function of latitude for the 18 December 1971 storm and compared with ground-based SAR arc observations. Two peaks in the energy loss profiles, at $L=4.4$ and 3.1, when adjusted for field line distortion appear to coincide with a double SAR arc, and have sufficient energy to drive them. For this same event, the ISIS-II analysis by Maier et al. (1975) showed at the same time a steep drop in $\mathrm{H}^{+}$at $\mathrm{L}=3$, , but no thermal plasma features at 3.75 (their low altitude equivalent of 4.4). This more poleward SAR arc is yet another example of a SAR arc lying poleward of the low altitude light ion trough.

Hultquist et al. (1976) have provided a helpful description of proton precipitation characteristics, with three distinctly identified regimes. The first is a region of isotropic proton precipitation lying outside the plasmapause, which is associated with auroral precipitation and which they term the "isotropic region." Its equatorward boundary is highly variable, depending on the activity level, varying from about $L=4.5$ to $L=7$. Equatorward of this is a "highly anisotropic region," with no measureable fluxes in the loss cone. Its low latitude boundary is relatively insensitive to disturbance level, so that it lies between $L=3.75$ and $L=4.25$. The third region is just equatorward of this, the "moderately anisotropic region," where protons again appear in the loss cone. Its inner boundary is nearly constant at about $L=2.75$. It is this region that is identified with SAR arcs. This association implies that the relevant proton instability requires a cold plasma density of about $10^{3} \mathrm{~cm}^{-3}$, since the region of the plasmasphere having this density $(L=3.5)$ is relatively unaffected by activity level.

\section{DISCUSSION AND CONCLUSIONS}

A schematic summary of the event is given in Fig. 8. Using the nomenclature of Hultqvist et al. (1976) the region poleward of the SAR arc is the isotropic region, where both protons and electrons are undergoing strong diffusion and reaching ionospheric levels. The highly anistropic region is absent so that we pass directly into a moderately anisotropic region of protons and electrons, with 


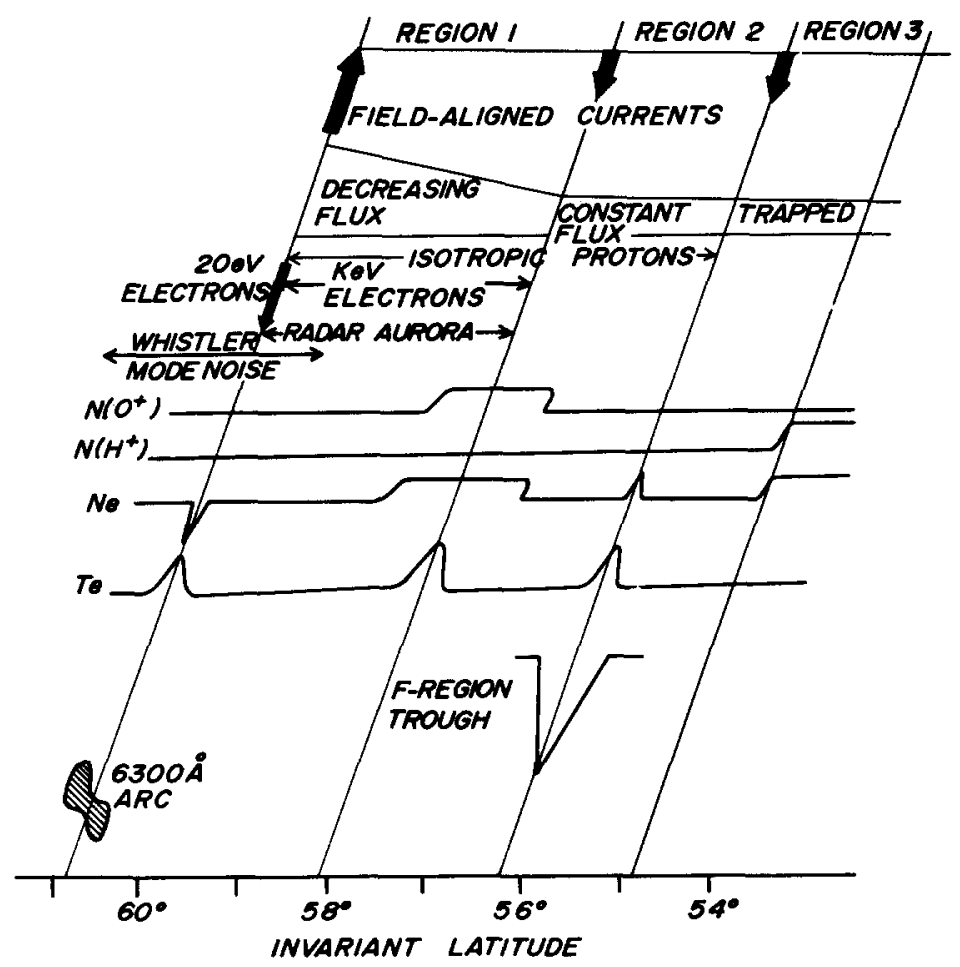

Fig. 8. A SCHEMATIC REPRESENTATION OF THE PHENOMENA ASSOCIATED WITH THE 4 AUgUST 1972 SAR ARC.

the boundary marked by the upward field-aligned current and the soft electrons. The first downward current marks the termination of the moderately anisotropic electrons (this can be seen in the paper by Shepherd et al., 1976) but the moderately anisotropic protons continue to the boundary marked by the second downward current. This boundary also marks the termination of solar energetic particles. Beyond this the trapped radiation belts begin. Our conclusions are as follows:

(1) For a SAR observed under recovery conditions, the ISIS-II spacecraft identifies a number of features in common with other observations. The SAR arc coincides with a gradient in the cold plasma density, an enhanced electron temperature and an $F$-region trough, all of which lie at the equatorward boundary of a region of moderately anisotropic protons.

(2) For both the recovery and development phase SAR arcs observed by ISIS-II, the following is observed. The electron temperature is high, with multiple peaks, throughout the region of proton occurrence, but the $6300 \AA$ arc seems to occur at only one of these peaks-normally in the electron trough. In both cases this trough is on the equatorward proton boundary.
(3) The 4 August 1972 development phase SAR arc had these unique features:

(a) it occurred at the poleward boundary of moderately anisotropic (nearly isotropic) proton precipitation;

(b) it coincided with an upward field-aligned current that seems to coincide with a beam of low energy electrons;

(c) the electron beam generated whistler mode noise in the range $0.1-0.4 \mathrm{MHz}$;

(d) the $6300 \AA$ emission has both a low energy electron excited component and a thermally excited component;

(e) the sharp proton poleward boundary, the field-aligned current and the electron beam coincide with a narrow and deep slot in the electron density at $1400 \mathrm{~km}$;

(f) the generation mechanism for the low energy electrons may be through kinetic Alfvén waves as proposed by Hasegawa and Mima (1978).

(4) Proton losses through precipitation cause electron temperature enhancements throughout the region of precipitation for all SAR arc events. SAR arcs appear at a specific region within this precipitation zone and may be associated with a specific instability or loss process. Normally SAR arcs ap- 
pear in the electron density trough at the equatorward boundary of the proton region, but the 4 August SAR arc appeared at the poleward boundary and was probably caused by a different type of instability process.

Acknowledgments-We are grateful to R. S. Unwin, P. J. Gill and J. G. Keys for kindly providing the New Zealand ground-based data. This work was supported by the National Research Council of Canada, and by NASA grant NGR23-005-015 and NGS 5085.

\section{REFERENCES}

Banks, P. M., Chappell, C. R. and Nagy, A. F. (1974). A new model for the interaction of auroral electrons with the atmosphere: spectral degredation backscatter, optical emission, and ionization. J. geophys. Res. 79, 1459.

Berko, F. W., Cahill, L. J. and Fritz, T. A. (1975). Protons as the prime contributors to storm time ring current. J. geophys. Res. 80, 3549.

Blake, J. B. (1976). On the ionic identity of the ring current particles. J. geophys. Res. 81, 6189.

Block, L. and Fälthammar, C.-G. (1968). Effects of fieldaligned currents on the structure of the ionosphere. $J$. geophys. Res. 73, 4807.

Brace, L. H., Maier, E. J., Hoffman, J. H., Whitteker, J. H. and Shepherd G. G. (1974). Deformation of the nightside plasmasphere and ionosphere during the August 1972 geomagnetic storm. J. geophys. Res. 79, 5211.

Bunn, F. E. and Shepherd, G. G. (1979). The solar terrestrial event of 14-21 December 1971: the pattern of $6300 \AA$ emission over the polar cap. Planet. Space Sci. 27, 973 .

Burrows, J. R., Wilson, M. D. and McDiarmid, I. B. (1976). Simultaneous field-aligned current and charged particle measurements in the cleft. Magnetospheric particles and fields, (Ed. B. M. McCormac), pp. 111-124, Reidel, Dordrecht, Holland.

Carpenter, D. L. (1971). OGO 2 and 4 VLF observations of the asymmetric plasmapause near the time of SAR arc events. J. geophys. Res. 76, 3644.

Chappell, C. R., Harris, K. K. and Sharp, G. W. (1971). OGO 5 measurements of the plasmasphere during observations of stable auroral red arcs. J. geophys. Res. 76, 2357

Chappell, C. R. (1972), Recent satellite measurements of the morphology and dynamics of the plasmasphere. Rev. geophys. Space Phys. 10, 951.

Cole, K. D. (1965). Stable auroral red arcs, sinks for energy of $D_{s t}$ main phase. J. geophys. Res. 70, 1689.

Cornwall, J. M., Coroniti, F. V. and Thorne, R. M. (1971). Unified theory of SAR arc formation at the plasmapause. $J$. geophys. Res. 76, 4428.

Foster, J. C., Park, C. G., Brace, L. H., Burrows, J. R., Hoffman, J. H., Maier, E. J. and Whitteker, J. H. (1978). Plasmapause signatures in the ionosphere and magnetosphere. J. geophys. Res. 83, 1175.

Hasegawa, A. and Mima, K. (1978). Anomalous transport produced by kinetic Alfvén wave turbulence, $J$. geophys. Res. 83, 1117.

Hays, P. B., Rusch, D. W., Roble, R. G. and Walker, J. C. G. (1978). The OI $(6300 \AA)$ airglow. Rev. geophys.
Space Phys. 16, 225.

Hoffman, J. H., Dodson, W. H., Lippincott, C. R. and Hammack, H. D. (1974). Initial ion composition results from the ISIS 2 satellite. J. geophys. Res. 79, 4246.

Hoffman, R. A., Cahill, L. J., Anderson, R. R., Maynard, R. C., Smith, P. H., Fritz, T. A., Williams, D. J., Konnadi, A. and Gurnett, D. A. (1975). J. geophys. Res. 80, 4287.

Hultqvist, B., Rielder, W. and Borg, H. (1976). Ring current protons in the upper atmosphere within the plasmasphere. Planet. Space Sci. 24, 783.

James, H. G. (1973). Whistler mode hiss at low and medium frequencies in the dayside-cusp ionosphere. $J$. geophys. Res. 78, 4578.

Kintner, P. M. and Gurnett, D. A. (1977). Observations of ion cyclotron waves within the plasmasphere by Hawkeye 1. J. geophys. Res. 82, 2314.

Lanzerotti, L. J., Hasegawa, A. and Maclennan, C. G. (1978). Hydromagnetic waves as a cuase of a SAR arc event. Planet. Space Sci. 26, 777.

Lundblad, J. A. and Soraas, F. (1978). Proton observations supporting the ion cyclotron wave heating theory of SAR arc formation. Planet Space Sci. 26, 245.

Lyons, L. R. and Evans, D. S. (1976). The inconsistency between proton charge exchange and the observed ring current decay. J. geophys. Res. 81, 6197.

Maggs, J. E. (1976). Coherent generation of VLF hiss. J. geophys. Res. 81, 1707.

Maier, E. J., Chandra, S., Brace, L., Hoffman, J. H., Shepherd, G. G. and Whitteker, J. H. (1975). The SAR arc event observed during the December 1971 magnetic storm. J. geophys. Res. 80, 4591.

Norton, R. B. and Findlay, J. A. (1969). Electron density and temperature in the vicinity of the 29 September 1967 middle latitude red arc. Planet Space Sci. 17, 1867.

Raitt, W. J. (1974). The temporal and spatial development of mid-latitude thermospheric electron temperature enhancements during a magnetic storm. J. geophys. Res. 79, 4703.

Rees, M. H. and Roble, R. G. (1975). Observations and theory of the formation of stable auroral red arcs. Rev. geophys. Space Phys. 13, 201.

Sharp, R. D., Johnson, R. G. and Shelley, E. G. (1976). The morphology of energetic $\mathrm{O}^{+}$ions during two magnetic storms; temporal variations. J. geophys. Res. 81, 3283 .

Shepherd, G. G. (1965). Storm time variation of aurora in the cis-auroral region, particularly the $6300 \AA$ line. Middle and Low Latitude Atmospheric Emissions and the Ionosphere, NBS Report 8824, p. 43.

Shepherd, G. G., Anger, C. D., Brace, L. H., Burrows, J. R., Heikkila, W. J., Hoffman, J. H., Maier, E. J. and Whitteker, J. H. (1973). An observation of polar aurora and airglow from the ISIS-II spacecraft. Planet. Space Sci. 21, 819 .

Shepherd, G. G., Burrows, J. R. and Cogger, L. L. (1976). Mid-latitude auroras and SAR arcs observed from the ISIS-II spacecraft during the August 1972 geomagnetic storm. J. geophys. Res. 81, 4597.

Smith, P. H., Hoffman, R. A. and Fritz, T. A. (1976). Ring current proton decay by charge exchange. $J$. geophys. Res, 81, 2701.

Stathopoulos, E. and McConnell, J. C. (1977). Unpublished work. 
Taylor, W. W. L. and Lyons, L. R. (1976). Simultaneous equatorial observations of $1-30 \mathrm{~Hz}$ waves and pitch angle distributions of ring current ions. $J$. geophys. Res. 81, 6177.

Tinsley, B. A. (1976). Evidence that the recovery phase ring currrent consists of helium ions. J. geophys. Res. 81, 6193.

Torr, M. R., Torr, D. G., Walker, J. C. G., Hays, P. B., Hanson, W. B., Hoffman, J. H. and Kayser, D. C. (1975). Effects of atomic nitrogen on the nocturnal ionosphere. Geophys. Res. Lett. 2, 385.

Unwin, R. S. (1979). Unpublished work.

Weber, E. J., Mende, S. B. and Eather, R. H. (1976).
Optical diagnostics of the August 1972 PCA event. J. geophys. Res. 81, 5479.

Williams, D. J. and Lyons, L. R. (1974a). The proton ring current and its interaction with the plasmapause: storm recovery phase. J. geophys. Res. 79, 4195.

Williams, D. J. and Lyons, L. R. (1974b). Further aspects of the proton ring current interaction with the plasniapause: main and recovery phases, J. geophys. Res. 79, 4791.

Williams, D. J., Hernandez, G. and Lyons, L. R. (1976). Simultaneous observations of the proton ring current and stable auroral red arcs. J. geophys. Res. 81, 608 . 